\title{
The Bacteriological Quality, Safety, and Antibiogram of Salmonella Isolates from Fresh Meat in Retail Shops of Bahir Dar City, Ethiopia
}

\author{
Melkamnesh Azage and Mulugeta Kibret \\ Department of Biology, Science College, Bahir Dar University, P.O. Box 79, Bahir Dar, Ethiopia \\ Correspondence should be addressed to Mulugeta Kibret; mulugetanig@gmail.com
}

Received 14 March 2017; Revised 7 June 2017; Accepted 14 June 2017; Published 25 July 2017

Academic Editor: Alejandro Castillo

Copyright ( 2017 Melkamnesh Azage and Mulugeta Kibret. This is an open access article distributed under the Creative Commons Attribution License, which permits unrestricted use, distribution, and reproduction in any medium, provided the original work is properly cited.

\begin{abstract}
The habit of raw meat consumption in addition to the poor hygienic standards and lack of knowledge contribute to food-borne diseases outbreaks. The objective of this research was to assess the bacterial quality and safety of fresh meat from retail Bahir Dar City, Ethiopia. A total of 30 fresh meat samples were collected from butcher shops. Standard bacteriological methods were used to isolate and enumerate bacteria. Kirby-Bauer disk diffusion method was used for antimicrobial susceptibility testing of Salmonella isolates. The mean counts of AMB, TC, and S. aureus were $\log _{10} 4.53,3.97$, and $3.88 \log _{10}$ cfu/g, respectively. Salmonella was isolated from 21 (70\%) of the samples. Salmonella isolates in this study were highly susceptible to ciprofloxacin, gentamycin, and norfloxacin while they were resistant to erythromycin and tetracycline. High rate of multiple drug resistance was also noticed in Salmonella isolates. The microbial loads of meat were above the recommended microbial safety limits. Besides this, the isolation rate of Salmonella was high and high levels of drug resistance were documented for Salmonella isolates. Measures on handling and appropriate personal hygiene practices of workers in the retail shops are recommended to reduce the change of forborne disease outbreaks.
\end{abstract}

\section{Introduction}

Meat is consumed by many people worldwide because of its nutritive composition. The protein profile of meat consists of amino acids that have been described as excellent due to the presence of all essential ones required by the body [1]. It is considered to be spoiled when it is unfit for human consumption and subjected to changes by its own enzyme, microbial action, and any other factors [2]. Enteric bacteria species can cause infections in humans when undercooked meat products are consumed [3]. The microbiological quality of meat depends on the physical status of the animal at slaughter, the spread of contamination during slaughter and processing, the temperature, and other conditions of storage and distribution [4]. The need for microbial assessment of fresh meats consumption is emphasized and recommended to reduce possible contamination [5].

In Ethiopia, minced or raw beef consumption is usually used for the preparation of a popular traditional Ethiopian dish known as locally "KITFO" and mostly it is consumed raw or partially cooked. This habit is a potential cause for foodborne illnesses in addition to, the common factors such as overcrowding, poverty, inadequate sanitary conditions, and poor general hygiene [6]. The microbiological quality of meat and meat products is very important with regard to public health significance. There are several reports on outbreaks of food-borne illnesses because of consumption of meat $[6,7]$. Moreover, antibiotic resistance levels are also elevated among food-borne pathogens such as Salmonella, E. coli, and Shigella [8-10].

The absence of organized slaughter house facility and the existence of small retail outlets have been the two biggest hurdles for hygienic production of meat [11]. It is essential to generate information about the quality of fresh beef sold in retail shops. Hence the present research work was undertaken to determine the bacteriological quality of the meat and determine the antimicrobial susceptibility profiles of Salmonella isolates from retail shops of Bahir Dar City, Ethiopia. 


\section{Materials and Methods}

2.1. Description of the Study Area. This study was conducted in May 2015 in Bahir Dar town, which is the capital of Amhara National Regional State (ANRS) situated in the northern part of Ethiopia. Bahir Dar is located at $11^{\circ} 36^{\prime} \mathrm{N}$ latitude and $37^{\circ} 23^{\prime} \mathrm{E}$ longitude and has an elevation of $1840 \mathrm{~m}$ above sea level. The area of the town is about $160 \mathrm{~km}^{2}$ and there are around 256,999 people living in there [12].

2.2. Sample Collection and Bacteriological Analysis. A crosssectional study was conducted in retail meat shops to determine bacteriological quality and antibiogram of Salmonella. A total of 30 retail cut meat samples were collected from 30 purposively selected retail houses between 7:00 and 9:00 am. One kilogram of cut meat was aseptically collected with sterile glove and placed in a sterile glass beaker covered with aluminum foil. The samples were transported to the laboratory in ice box and bacteriological analysis was done within two hours of collection at Food Microbiology Laboratory of School of Chemical and Food Engineering, Bahir Dar University. The ambient temperature at the time of sample collection was $20^{\circ} \mathrm{C}$.

Twenty-five grams of meat sample was mixed with $225 \mathrm{ml}$ of $0.1 \%$ buffered peptone water (Merck, Darmstadt) and homogenized for 2 minutes by using stomacher (Seward Ltd., UK) [13]. Tenfold serial dilutions $\left(10^{-2}-10^{-4}\right)$ were made from the homogenized sample and $1 \mathrm{ml}$ from each sample of each dilution was taken and used for enumeration of aerobic mesophilic bacteria (AMB), total coliforms (TC), and $S$. aureus and the remaining homogenate was used for the isolation of Salmonella.

Enumeration of aerobic mesophilic bacteria was done using the pour plate techniques on plate count agar (Oxoid, England). One $\mathrm{ml}$ of homogenized sample was inoculated onto plate count agar, in triplicate and the plates were incubated aerobically at $32^{\circ} \mathrm{C}$ for a maximum of $48 \mathrm{hrs}$. After incubation, the plates having 30-300 colonies were counted using colony counter. Uninoculated media were incubated as negative control to check for sterility [14]. Violate Red Bile Agar (VRBA) (Oxoid, England) was used to count total coliforms after incubation at $30-37^{\circ} \mathrm{C}$ for $24-48 \mathrm{hrs}$, by using pour plate technique. All purplish red colonies were counted as coliforms [15]. For Staphylococcus aureus count, samples were spread-plated in triplicate plates of Mannitol Salt Agar (Oxoid, England) and incubated at $30-37^{\circ} \mathrm{C}$ for $48 \mathrm{hrs}$ and yellow colonies were counted $[14,15]$.

2.3. Isolation of Salmonella. The homogenized sample was incubated at $37^{\circ} \mathrm{C}$ for $24 \mathrm{hrs}$ and $1 \mathrm{ml}$ of culture was transferred to $10 \mathrm{ml}$ of selenite cysteine broth (SCB) (Himedia, India) and incubated further at $37^{\circ} \mathrm{C}$ for $24 \mathrm{hrs}$. A loop full of culture from selenite cysteine broth culture was subcultured onto Xylose lysine deoxycholate (XLD) agar (Oxoid, England) plate and incubated aerobically at $37^{\circ} \mathrm{C}$ for $24 \mathrm{hrs}$. After incubation, 2-3 characteristic colonies of Salmonella (red colonies with or without black center) were picked and stored on Tryptic Soya Agar (TSA) slants for further purification and used for biochemical characterization and antimicrobial susceptibility tests [16].

2.4. Antimicrobial Susceptibility Testing of Salmonella Isolates. In vitro antimicrobial susceptibility tests were performed on Mueller-Hinton agar (Oxoid, UK) using Kirby-Bauer disk disc diffusion technique [17]. The antimicrobials tested were ciprofloxacin (CIP, $5 \mu \mathrm{g}$ ), norfloxacin (NOR, $10 \mu \mathrm{g}$ ), amoxicillin (AMC, $30 \mu \mathrm{g}$ ), ampicillin (AMP, $10 \mu \mathrm{g}$ ), chloramphenicol $(\mathrm{C}, 30 \mu \mathrm{g})$, erythromycin $(\mathrm{E}, 15 \mu \mathrm{g})$, gentamicin (CN, $10 \mu \mathrm{g}$ ), nalidixic acid (NA, $30 \mu \mathrm{g}$ ), trimethoprim-sulfamethoxazole (SXT, $25 \mu \mathrm{g}$ ), cefoxitin (FOX, $30 \mu \mathrm{g}$ ), and tetracycline (TE, $30 \mu \mathrm{g}$ ) (Oxoid, UK). Morphologically identical 4-6 bacterial colonies from overnight culture were suspended in $5 \mathrm{ml}$ nutrient broth and incubated for $4 \mathrm{hrs}$ at $37^{\circ} \mathrm{C}$. Turbidity of the broth culture was equilibrated to match 0.5 McFarland standards. The surface of Mueller-Hinton agar plate was evenly inoculated with the culture using a sterile cotton swab. The antibiotic discs were applied to the surface of the inoculated agar. After 18-24 hrs of incubation, the diameter of growth inhibition around the discs was measured and interpreted as sensitive, intermediate, or resistant according to Clinical and Laboratory Standards Institute [18]. Reference strain of E. coli ATCC 25922 was used as quality control for antimicrobial susceptibility tests.

2.5. Data Analysis. Data were analyzed using the statistical package for Social Science (SPSS) version 20 software by descriptive statistics. Results of bacterial counts were expressed in terms of mean log $\mathrm{cfu} / \mathrm{g}$ and compared with Gulf Standards, 2002 [19] (Table 1). The isolation rate of Salmonella prevalence and antimicrobial susceptibility tests were expressed in terms of percentage.

\section{Results and Discussion}

In this study, the aerobic mesophilic bacteria counted in fresh meat ranged between 1.91 and $6.70 \log _{10} \mathrm{cfu} / \mathrm{g}$ having a mean value of $4.53 \log _{10} \mathrm{cfu} / \mathrm{g}$ (Table 2). All 30 samples of fresh meat had high counts of aerobic mesophilic bacteria. In the current study, the total coliform counts detected ranged between 1.40 and $6.50 \log _{10} \mathrm{cfu} / \mathrm{g}$ having a mean value of $3.97 \log _{10} \mathrm{cfu} / \mathrm{g}$. The mean count of $S$. aureus in fresh meat in this study was $3.88 \log _{10} \mathrm{cfu} / \mathrm{g}$ and ranged between 1.42 and $8.47 \log _{10} \mathrm{cfu} / \mathrm{g}$ (Table 2).

Aerobic mesophilic count is one of the microbiological indicators for food quality and the presence of aerobic organisms reflects existence of favorable conditions for the multiplication of microorganisms [20]. Coliforms are indicators of water or food quality and their presence may be an indication of unhygienic condition [21]. The highest number of $S$. aureus on meat indicates the presence of cross-contamination, which usually related to human skin, hair, hand and discharge from nose, and clothing. High contamination of food with $S$. aureus has been related to improper personal hygiene of employees during handling and processing [12].

The results of this study are comparable to the findings of previous works [22-24]. Other researchers have reported higher and lower aerobic mesophilic, coliform, and $S$. aureus 
TABLE 1: Guideline levels for determining microbial quality of ready-to-eat food (Gulf Standards and NSW Food Authority).

\begin{tabular}{lcccc}
\hline Microbial groups & Good & Acceptable & Unsatisfactory & Unacceptable and potentially dangerous \\
\hline Aerobic mesophilic count & $<10^{4}$ & $10^{4}-<10^{6}$ & $\geq 10^{6}$ & N/A \\
Total coliform count & $<10^{2}$ & $10^{2}-10^{4}$ & $\geq 10^{4}$ & N/A \\
S. aureus count & $<10^{2}$ & $10^{2}-10^{3}$ & $10^{3}-<10^{4}$ & $\geq 10^{4}$ \\
Pathogens & Not detected in 25 g of & - & - & Detected in 25 g of \\
\hline
\end{tabular}

TABle 2: Bacterial counts of fresh meat in Bahir Dar town, May, 2015.

\begin{tabular}{lccc}
\hline Bacterial counts & $\begin{array}{c}\text { Minimum count } \\
\left(\log _{10} \mathrm{cfu} / \mathrm{g}\right)\end{array}$ & $\begin{array}{c}\text { Maximum } \\
\text { count } \\
\left(\log _{10} \mathrm{cfu} / \mathrm{g}\right)\end{array}$ & $\begin{array}{c}\text { Mean } \pm \text { SD } \\
\left(\log _{10} \mathrm{cfu} / \mathrm{g}\right)\end{array}$ \\
\hline AMC & 1.91 & 6.70 & $4.53 \pm 1.24$ \\
TC & 1.40 & 6.50 & $3.97 \pm 1.42$ \\
S. aureus & 1.42 & 8.47 & $3.88 \pm 1.81$ \\
\hline
\end{tabular}

TABle 3: Antibiotic susceptibility pattern of Salmonella isolates in Bahir Dar town, May, 2015.

\begin{tabular}{lccr}
\hline Antimicrobial Agents & Resistant No (\%) & Intermediate No (\%) & Sensitive No (\%) \\
\hline Ciprofloxacin & $0(0)$ & $0(0)$ & $21(100)$ \\
Nalidixic acid & $0(0)$ & $2(9.5)$ & $19(90.5)$ \\
Erythromycin & $19(90.5)$ & $2(9.5)$ & $0(0)$ \\
Ampicillin & $5(23.8)$ & $4(19)$ & $12(57.2)$ \\
Tetracycline & $14(66.7)$ & $0(0)$ & $7(33.3)$ \\
Trimethoprim-sulfamethoxazole & $2(9.5)$ & $0(0)$ & $19(90.5)$ \\
Gentamycin & $0(0)$ & $0(0)$ & $21(100)$ \\
Cefoxitin & $2(9.5)$ & $7(33.3)$ & $12(57.2)$ \\
Amoxicillin & $2(9.5)$ & $2(9.5)$ & $17(81)$ \\
Chloramphenicol & $0(0)$ & $1(4.8)$ & $20(95.2)$ \\
Norfloxacin & $0(0)$ & $0(0)$ & $21(100)$ \\
\hline
\end{tabular}

counts [25-27]. The differences might be as a result of differences in study areas, temperature, and personal hygiene practices of the vendors.

The total aerobic counts far exceed the prescribed microbiological safety limits of Gulf Standards [19]. The implication of the findings is that the product is not safe for human consumption, since the samples had counts of aerobic counts exceeding the acceptable limits [28]. In general most of the raw meats sold at butcher shops in this study were potentially hazardous for health.

Among 30 meat samples tested, 21 (70\%) were positive for Salmonella. Salmonella isolates exhibited high level of resistance to erythromycin and tetracycline. The isolates were sensitive to ciprofloxacin, gentamycin, and norfloxacin. There were also intermediate levels of resistances to cefoxitin, ampicillin, and nalidixic acid (Table 3). Among 21 isolates of Salmonella, $15(71.43 \%)$ were resistant to two or more antibiotics. Five of the isolates were resistant to three or more antibiotics (Table 4).

With regard to the antimicrobial susceptibility profiles of Salmonella isolates, all the Salmonella isolates showed high level of sensitivity (95-100\%) to gentamycin, ciprofloxacin, norfloxacin, and chloramphenicol while high levels of resistance (66-90\%) were documented against erythromycin and
TABLE 4: MDR pattern of salmonella isolates in Bahir Dar town, June, 2015.

\begin{tabular}{lc}
\hline Resistance pattern & Salmonella isolates No (\%) \\
\hline Resistant to two antibiotics & \\
E-TE & $8(38)$ \\
E- SXT & $1(4.8)$ \\
TE-AMP & $1(4.8)$ \\
Resistant to three antibiotics & \\
E-TE-AMP & $2(9.5)$ \\
Resistant to four antibiotics & \\
E-TE-AMP-AMC & $1(4.8)$ \\
E-TE-AMP- SXT & $1(4.8)$ \\
E-TE-FOX-AMC & $1(4.8)$ \\
\hline
\end{tabular}

tetracycline. From a study done in Ethiopia, Reda et al. [29] and Farzana et al. [30] reported comparable levels of sensitivity and resistance This could be due to the fact that ciprofloxacin and norfloxacin are relatively expensive and newly introduced, compared to the other common antibiotics. The routine practice of giving antimicrobial agents to domestic livestock as a means of preventing and treating diseases, 
as well as promoting growth, is an important factor in the emergence of antibiotic-resistant bacteria that are subsequently transferred to humans through the food chain [31, 32]. Most infections with antimicrobial-resistant Salmonella are acquired by eating contaminated foods of animal origin $[33,34]$.

\section{Conclusion}

This study revealed high level of contamination in fresh meat as indicated by high aerobic mesophilic, S. aureus, and coliform counts which are above the recommended microbial safety limits. High bacterial loads and isolation of drug resistant Salmonella suggest a potential health risk to the consumers from the consumption of raw meat. These indicate poor handling and personal hygiene practices of workers in the retail shops and risk of food-borne disease. Investigation on antibiotic use in animal and animal feed is recommended.

\section{Conflicts of Interest}

The authors declare that there are no conflicts of interest regarding the publication of this paper.

\section{References}

[1] O. A. Olaoye, "Meat: an overview of its composition, biochemical changes and associated microbial agents," International Food Research Journal, vol. 18, no. 3, pp. 877-885, 2011.

[2] K. Bradeeba and P. K. Sivakumaar, "Assessment of microbiological quality of beef, mutton and pork and its environment in retail shops in Chidambaram, Tamil Nadu," International Journal of Plant, Animal and Environmental Sciences, vol. 3, pp. 9197, 2013.

[3] C. N. Ateba and T. Setona, "Isolation of enteric bacterial pathogens from raw mince meat in mafikeng, north-west province," South Africa Life Science Journal, vol. 8, no. 2, pp. 1-7, 2011.

[4] A. J. Ilboudo, F. Tapsoba, A. Savadogo, M. Seydi, and A. S. Traore, "Improvement of the hygienic quality of farmhouse meat pies produced in Burkina Faso," Advances in Environmental Biology, vol. 6, no. 10, pp. 2627-2635, 2012.

[5] I.-O. E. Ukut, I. O. Okonko, I. S. Ikpoh et al., "Assessment of bacteriological quality of fresh meats sold in Calabar Metropolis, Nigeria," Electronic Journal of Environmental, Agricultural and Food Chemistry, vol. 9, no. 1, pp. 89-100, 2010.

[6] M. Birhaneselassie and D. Williams, "A Study of Salmonella carriage among asymptomatic food-handlers in Southern Ethiopia," International Journal of Nutrition and Food Sciences, vol. 2, no. 5, pp. 243-245, 2013.

[7] S. G. Bhandare, A. T. Sherikar, A. M. Paturkar, V. S. Waskar, and R. J. Zende, "A comparison of microbial contamination on sheep/goat carcasses in a modern Indian abattoir and traditional meat shops," Food Control, vol. 18, no. 7, pp. 854-858, 2007.

[8] M. Kibret and M. Tadesse, "The bacteriological safety and antimicrobial susceptibility of bacteria isolated from streetvended white lupin (Lupinus albus) in Bahir Dar, Ethiopia," Ethiopian Journal of Health Sciences, vol. 23, no. 1, pp. 19-26, 2013.

[9] L. Garedew, Z. Hagos, Z. Addis, R. Tesfaye, and B. Zegeye, "Prevalence and antimicrobial susceptibility patterns of Salmonella isolates in association with hygienic status from butcher shops in Gondar town, Ethiopia," Antimicrobial Resistance and Infection Control, vol. 4, no. 1, article 21, 2015.

[10] E. Khan, K. Jabeen, M. Ejaz, J. Siddiqui, M. F. Shezad, and A. Zafar, "Trends in antimicrobial resistance in Shigella species in Karachi, Pakistan," Journal of Infection in Developing Countries, vol. 3, no. 10, pp. 798-802, 2009.

[11] P. Kumar, J. Rao, Y. Haribabu, and . Manjunath, "Microbiological Quality of Meat Collected from Municipal Slaughter Houses and Retail Meat Shops from Hyderabad Karnataka Region, India," APCBEE Procedia, vol. 8, pp. 364-369, 2014.

[12] CSA (Central Statistical Authority of Ethiopia), “The 2010 Population and Housing Census of Ethiopia," 2011.

[13] R. Jacob Microbial quality of ready- to-eat foods available to populations of different demographics, A Master Thesis Submitted to the Faculty of Drexel University, Philadelphia, Pa, USA, 2010.

[14] M. U. D. Ahmad, A. Sarwar, M. I. Najeeb et al., "Assessment of microbial load of raw meat at abattoirs and retail outlets," Journal of Animal and Plant Sciences, vol. 23, pp. 745-748, 2013.

[15] A. Chaiba, F. F. Rhazi, A. Chahlaoui et al., "Microbiological quality of poultry meat on the Meknes Market (Morocco)," Internet Journal of Food Safety, vol. 9, pp. 67-71, 2007.

[16] WHO, "Global Salm-Surv: a global Salmonella surveillance and laboratory support project of the World Health Organization," 2003.

[17] A. Bauer, W. Kirby, J. Sheriss, and M. Turk, "Antibiotic susceptibility testing by standard single disk diffusion method," American Journal of Clinical Pathology, vol. 45, pp. 493-496, 1966.

[18] Clinical and Laboratory Standards Institute, Performance Standards for Antimicrobial Susceptibility Testing; Seventeenth Information Supplement, CLSI document M100-S17, Clinical and Laboratory Standards Institute, Wayne, Pa, USA, 2011.

[19] Microbiological Criteria for Food Stuffs-part 1. GCC, Gulf Region Standards, Riyadh, Saudi Arabia, 2000.

[20] M. E. Nyenje, C. E. Odjadjare, N. F. Tanih, E. Green, and R. N. Ndip, "Foodborne pathogens recovered from ready-to-eat foods from roadside cafeterias and retail outlets in alice, eastern cape province, South Africa: public health implications," International Journal of Environmental Research and Public Health, vol. 9, no. 8, pp. 2608-2619, 2012.

[21] N. Ejikeme and N. V. Ugochukwu, "Occurrence of Staphylococcus aureus in meat pie and egg roll sold in Umuahia Metropolis, Nigeria," International Journal of Microbiology Immunology Research, vol. 1, pp. 52-55, 2013.

[22] N. Badrie, A. Joseph, and A. Chen, "An observational study of food safety practices by street vendors and microbiological quality of street-purchased hamburger beef patties in Trinidad, West Indies," Internet Journal of Food Safety, vol. 3, pp. 25-31, 2001.

[23] A. Gebeyehu, M. Yousuf, and A. Sebsibe, "Evaluation of microbial load of beef of Arsi cattle in Adama Town, Oromia, Ethiopia," Journal of Food Process Technology, vol. 4, pp. 1-6, 2013.

[24] A. U. Nnachi and C. O. Ukaegbu, "Microbial quality of raw meat sold in Onitsha, Anambra State, Nigeria," International Journal of Scientific Research, vol. 3, pp. 214-218, 2014.

[25] R. Koffi-Nevr, M. Koussemon, and S. O. Coulibaly, "Bacteriological Quality of Beef Offered for Retail Sale in Cote d'Ivoire," American Journal of Food Technology, vol. 6, no. 9, pp. 835-842, 2011. 
[26] N. Cohen, H. Ennaji, M. Hassa, and H. Karib, "The bacterial quality of red meat and offal in Casablanca (Morocco)," Molecular Nutrition and Food Research, vol. 50, no. 6, pp. 557-562, 2006.

[27] J. A. Khan and I. Shukla, "Re-emergence of chloramphenicol sensitive Salmonella Enteric serotype Typhi-a preliminary report," BioNotes, vol. 6, p. 50, 2004.

[28] M. D. Salihu, A. U. Junaidu, A. A. Magaji et al., "Bacteriological quality of traditionally prepared fried ground beef (Dambun nama) in Sokoto, Nigeria," Advance Journal of Food Science and Technology, vol. 2, no. 3, pp. 145-147, 2010.

[29] A. Reda, B. Seyoum, J. Yimam et al., "Antibiotic susceptibility patterns of Salmonella and Shigella isolates in Harer, Eastern Ethiopia," Journal of Infectious Diseases and Immunity, vol. 3, pp. 34-39, 2011.

[30] K. Farzana, M. R. Akram, and S. Mahmood, "Prevalence and antibiotics susceptibility patterns of some bacterial isolates from a street vended fruit product," African Journal of Microbiology Research, vol. 5, no. 11, pp. 1277-1284, 2011.

[31] L. Tollefson, S. F. Altekruse, and M. E. Potter, "Therapeutic antibiotics in animal feeds and antibiotic resistance," Revue Scientifique et Technique, vol. 16, no. 2, pp. 709-715, 1997.

[32] W. Witte, "Medical consequences of antibiotic use in agriculture," Science, vol. 279, no. 5353, pp. 996-997, 1998.

[33] F. J. Angulo, K. R. Johnson, R. V. Tauxe, and M. L. Cohen, "Origins and consequences of antimicrobial-resistant nontyphoidal Salmonella: implications for the use of fluoroquinolones in food animals," Microbial Drug Resistance, vol. 6, no. 1, pp. 77-83, 2000.

[34] P. D. Fey, T. J. Safranek, M. E. Rupp et al., "Ceftriaxone-resistant Salmonella infection acquired by a child from cattle," New England Journal of Medicine, vol. 342, no. 17, pp. 1242-1249, 2000 . 

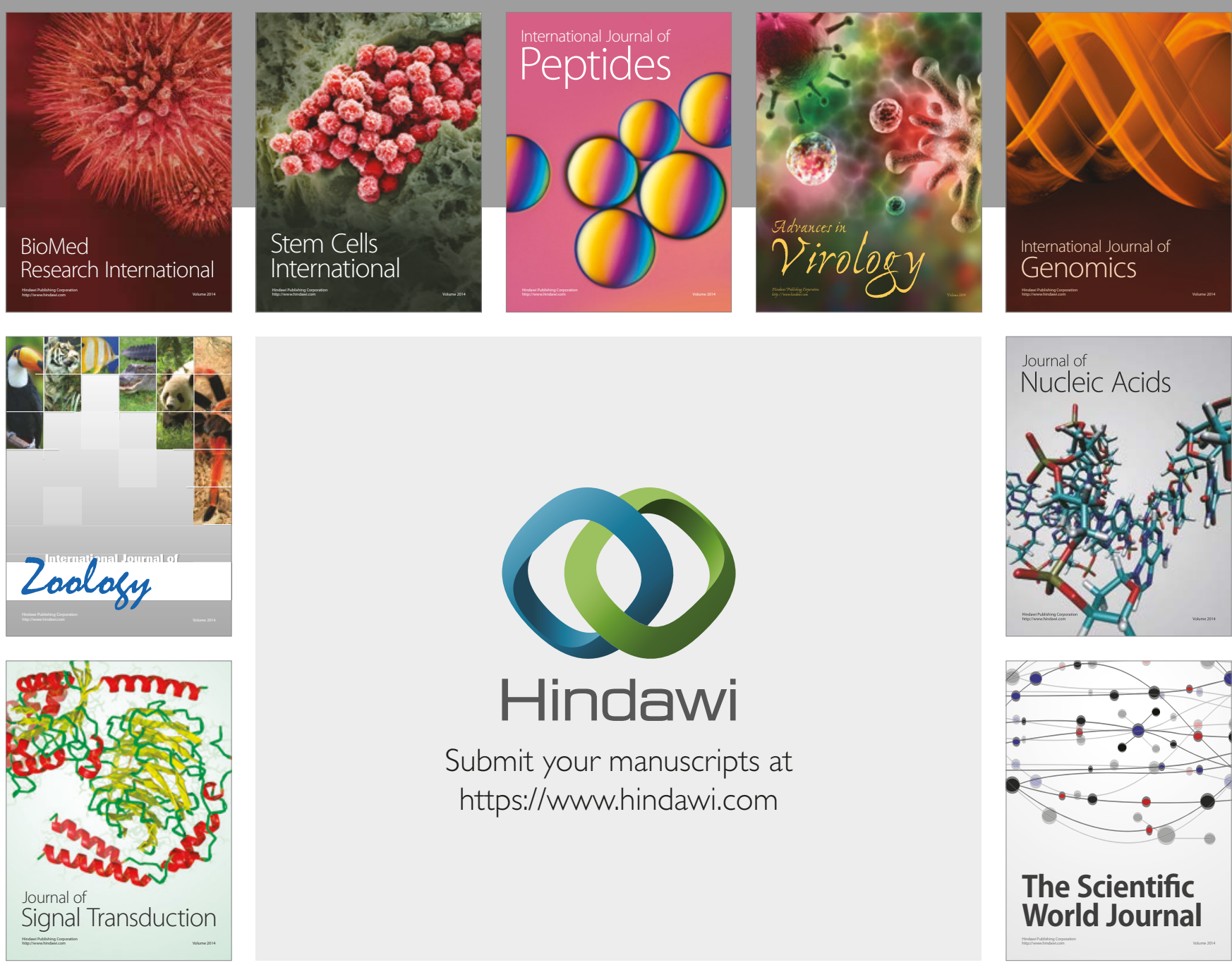

Submit your manuscripts at

https://www.hindawi.com
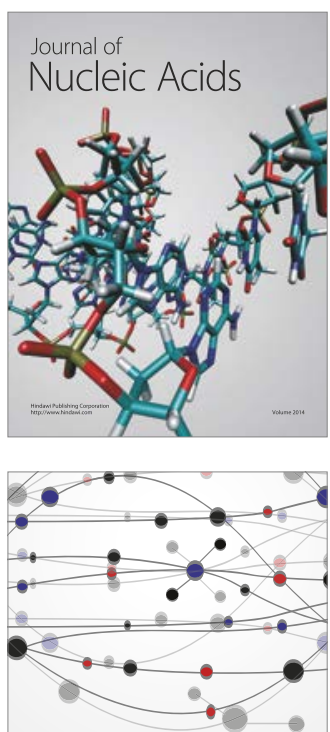

The Scientific World Journal

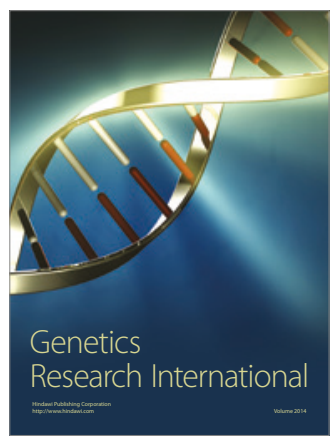

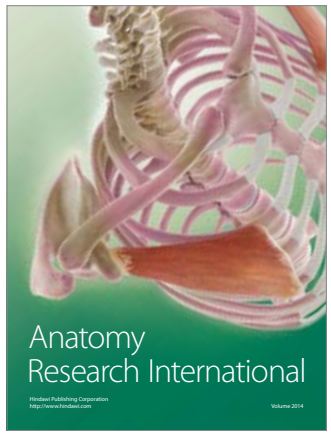

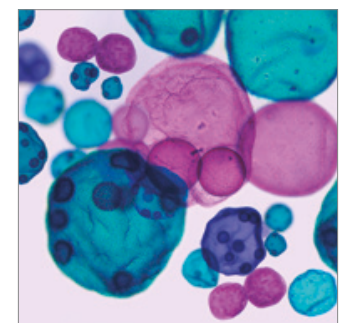

International Journal of Microbiology
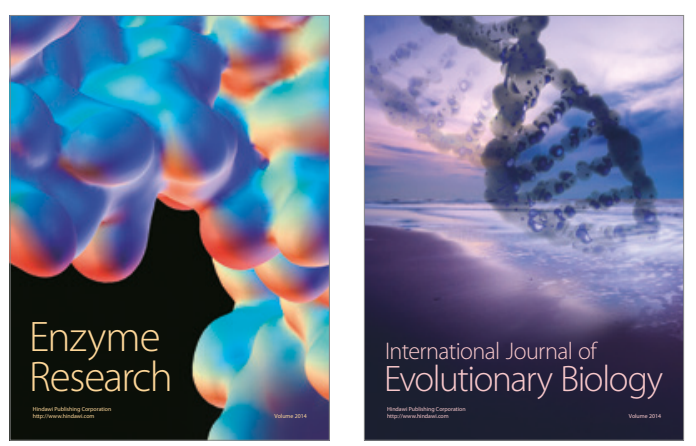
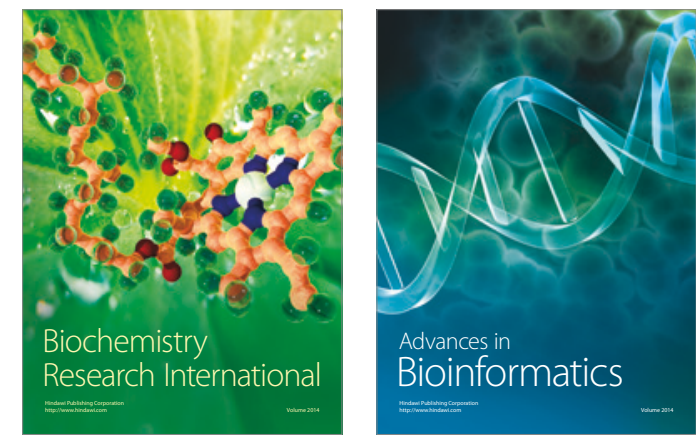

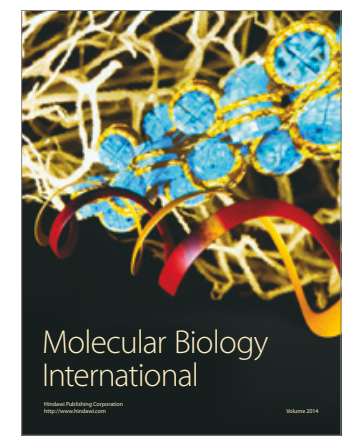

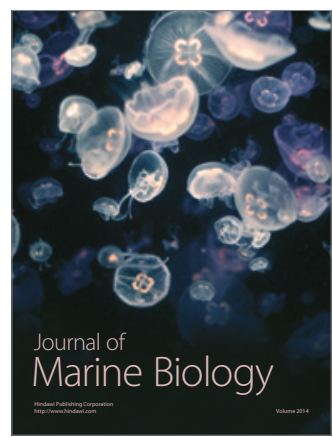

